\title{
La formación pedagógica del docente rural con el apoyo de las tecnologías como una herramienta de enseñanza- aprendizaje en el aula
}

Pedagogical training of rural teachers with the support of technologies as a
teaching-learning tool in the classroom

A formação pedagógica de professores rurais com o apoio de tecnologias como ferramenta de ensino-aprendizagem em sala de aula

Francisco Flores Cuevas

Universidad de Guadalajara, Centro Universitario de la Costa, México francisco.fcuevas@academicos.udg.mx https://orcid.org/0000-0002-8874-9918

Claudio Rafael Vásquez Martínez Universidad de Guadalajara, Centro Universitario de la Costa, México crvasquezm@gmail.com https://orcid.org/0000-0001-6383-270X

Heriberto Campos López Universidad de Guadalajara, Centro Universitario de la Costa, México

hcamposl@gmail.com https://orcid.org/0000-0002-7922-5987 


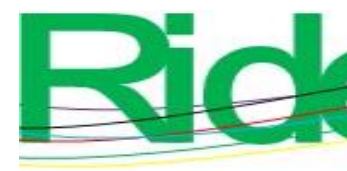

Revista Iberoamericana para la Investigación y el Desarrollo Educativo ISSN 2007 - 7467

\section{Resumen}

El presente trabajo se enfoca en el estudio de los procesos formativos de docentes de educación rural que laboran en la región del Tequendama, departamento de Cundinamarca (Colombia), específicamente en tres instituciones ubicadas en el municipio de San Antonio del Tequendama. Este objeto de análisis fue elegido debido a la necesidad que existe de estudiar la formación docente tanto en aspectos pedagógicos como en el uso de las herramientas tecnológicas, conocimientos esenciales para mejorar la calidad formativa en los diversos niveles educativos. Los participantes, elegidos por conveniencia, fueron 90 maestros y maestras que laboraban en el año lectivo 2019. Para recabar la información se empleó una encuesta constituida por 27 preguntas en las que se relacionaron la formación del docente rural y el conocimiento y uso de las TIC en el aula. Los resultados demuestran, en cuanto a las TIC, que esos medios tecnológicos son usados por los docentes más para fines particulares y personales que pedagógicos, por lo que no han tenido el impacto esperado dentro de los procesos de enseñanza-aprendizaje. Además, cabe señalar que en el presente trabajo se ha evidenciado que los maestros no han sido formados para el trabajo en zonas rurales, ambientes en los cuales se presentan particularidades y necesidades muy distintas a las de las zonas urbanas.

Palabras clave: calidad de la educación, educación comunitaria, educación permanente, tecnologías de la información y comunicación.

\section{Abstract}

This paper focuses on the study of the training processes of rural education teachers who work in the Tequendama region, department of Cundinamarca (Colombia), specifically in three institutions located in the municipality of San Antonio del Tequendama. This object of analysis was chosen due to the need to study teacher training both in pedagogical aspects and in the use of technological tools, essential knowledge to improve the quality of training at various educational levels. The participants, chosen for convenience, were 90 teachers who worked in the 2019 school year. To collect the information, a survey consisting of 27 questions was used in which the training of rural teachers and the knowledge and use of ICT were related. in the classroom. The results show, in terms of ICT, that these technological means are used by teachers more for private and personal purposes than pedagogical, so they have not had the expected impact within the teaching-learning processes. In addition, it 

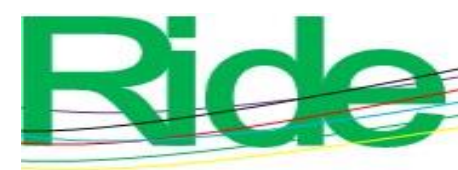

Revista Iberoamericana para la Investigación y el Desarrollo Educativo

ISSN $2007-7467$

should be noted that in this work it has been shown that teachers have not been trained for work in rural areas, environments in which there are particularities and needs that are very different from those of urban areas.

Keywords: Quality of education, community education, lifelong education, information and communication technologies.

\section{Resumo}

Este artigo se concentra no estudo dos processos de formação de professores de educação rural que atuam na região de Tequendama, departamento de Cundinamarca (Colômbia), especificamente em três instituições localizadas no município de San Antonio del Tequendama. Este objeto de análise foi escolhido devido à necessidade de estudar a formação de professores tanto nos aspectos pedagógicos como na utilização de ferramentas tecnológicas, conhecimentos essenciais para melhorar a qualidade da formação nos diversos níveis de ensino. Los participantes, elegidos por conveniencia, fueron 90 maestros y maestras que laboraban en el año lectivo 2019. Para recabar la información se empleó una encuesta constituida por 27 preguntas en las que se relacionaron la formación del docente rural y el conocimiento y uso de las TIC na aula. Os resultados mostram, em termos de TIC, que estes meios tecnológicos são utilizados pelos professores mais para fins particulares e pessoais do que pedagógicos, pelo que não tiveram o impacto esperado nos processos de ensinoaprendizagem. Além disso, deve-se destacar que neste trabalho foi demonstrado que os professores não foram capacitados para atuar no meio rural, ambientes em que existem particularidades e necessidades muito distintas das do meio urbano.

Palavras-chave: qualidade da educação, educação comunitária, educação ao longo da vida, tecnologias de informação e comunicação.

Fecha Recepción: Agosto 2020

Fecha Aceptación: Marzo 2021 


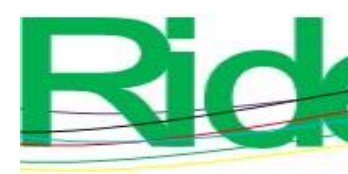

Revista Iberoamericana para la Investigación y el Desarrollo Educativo ISSN $2007-7467$

\section{Introducción}

El presente trabajo se enfoca en el estudio de los procesos formativos de algunos docentes de educación rural que laboran en la región del Tequendama, departamento de Cundinamarca (Colombia), específicamente en determinadas instituciones ubicadas en el municipio de San Antonio del Tequendama. Este objeto de análisis fue elegido debido a la necesidad que existe de estudiar la formación docente tanto en aspectos pedagógicos como en el uso de las herramientas tecnológicas, conocimientos esenciales para mejorar la calidad formativa en los diversos niveles educativos. Con base en esta premisa, se han formulado las siguientes preguntas de investigación:

Pregunta principal: ¡cómo favorecer la formación de los docentes mediante el uso de las TIC en el contexto rural de la región del Tequendama (departamento de Cundinamarca, Colombia) para mejorar la calidad educativa en dicha comunidad y en otras zonas?

Preguntas secundarias: ¿qué tan importantes son la experiencia docente y la formación en el uso y manejo de las TIC en los procesos de enseñanza-aprendizaje en el nivel educativo de secundaria en una zona rural?, ¿cuál es el nivel de conocimiento por parte de los docentes sobre el uso y dominio de las TIC y cómo esto impacta en la secundaria de una zona rural $?, ¿$ los docentes de secundaria de esa zona rural qué tanto usan y dominan las TIC como estrategias pedagógicas y metodológicas para mejorar cada uno de los procesos de enseñanza-aprendizaje?, ¿cuál ha sido el efecto motivador del uso y manejo de las TIC como estrategia pedagógica y metodológica en cada uno de los procesos de enseñanza-aprendizaje dentro del aula?

Premisa de investigación (hipótesis): la formación pedagógica, así como el uso y manejo de las TIC dentro del proceso de enseñanza-aprendizaje han sido insuficientes para mejorar la calidad de la educación y el fortalecimiento de competencias de los docentes que imparten clases en la zona del Tequendama (departamento de Cundinamarca, Colombia).

\section{Antecedentes y justificación}

Según Barroso (2012), “conceptualizar el nuevo papel del profesor en la práctica educativa cotidiana y real conlleva situarlo en la idea de la posmodernidad y en el concepto de globalización, ya que ésta última relativiza todo lo que toca en su movimiento expansivo" (p. 202). En este sentido, "la posmodernidad ha ejercido una fuerte influencia en la naturaleza de la vida intelectual en una variedad de disciplinas, tanto en la universidad como fuera de 


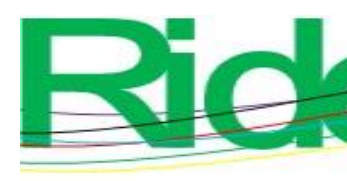

Revista Iberoamericana para la Investigación y el Desarrollo Educativo ISSN $2007-7467$

ella" (Cabero, 2015, p. 218), lo que "representa un estado de ánimo, una manera de nombrar diversos fenómenos que tiene que ver con la incertidumbre de nuestros días" (De Pablos, 2007, p. 48). Por lo anterior, cabe hacer mención que "Las TIC posibilitan poner en práctica estrategias comunicativas y educativas para establecer nuevas formas de enseñar y aprender, mediante el empleo de concepciones avanzadas de gestión, en un mundo cada vez más exigente y competitivo, donde no hay cabida para la improvisación” (Koskinen, 1999, p. 79).

\section{Referentes teórico-contextuales}

En cuanto a las bases teóricas, en esta investigación se han tomado diversos referentes para procurar tener una visión más precisa del tema objeto de estudio (Brunner, 2011, p. 227). Por eso, se han desarrollado las siguientes categorías: proceso de enseñanza-aprendizaje en el ámbito educativo, incidencia de las TIC en dicho proceso, lo rural en el territorio colombiano, la formación del docente para una educación rural y su caracterización atendiendo a diversas perspectivas. Igualmente, se realiza una aproximación a las implicaciones y a la definición de calidad educativa. Para finalizar, se trata el problema de la equidad y cómo esta afecta la calidad en la educación.

\section{Calidad educativa}

En los siguientes conceptos se muestra una clara evolución de lo que es la calidad y que en cada una de ellas se han construidos en diversas circunstancias y han ido evolucionando y atendiendo a diferentes necesidades.

Para Beeby (1976) establece que "es importante distinguir y contrastar entre la calidad del producto y la calidad del proceso, siendo esta última más importante ya que es el valor adicionado que tienen las escuelas y los sistemas educativos” (p. 27). Asimismo, destaca dos concepciones de calidad: "la calidad interna, que responde al cumplimiento de las metas propuestas a alcanzar; y la calidad vista como idoneidad, es decir, que el sistema sea adecuado para producir la clase de personas que la sociedad necesita".

Por otra parte, una institución educativa puede poseer alta calidad interna, pero carecer de idoneidad; o viceversa. Por lo tanto, la calidad de la educación depende de la presencia de estás dos dimensiones. Para García Hoz (1981) la referencia explícita a la calidad dentro del ámbito educativo es "reciente y viene determinada por el derecho a la educación, el cual no sólo se debe aplicar en términos de cantidad sino también de calidad" 


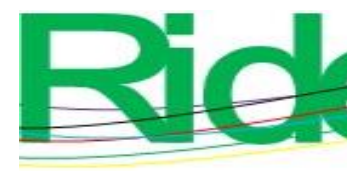

Revista Iberoamericana para la Investigación y el Desarrollo Educativo

ISSN $2007-7467$

(pp. 9-23). Además, el mismo autor la define a la calidad educativa como: "el modo de ser de la educación que reúne las características de integridad, coherencia y eficacia” (pp. 9-23). En otras palabras, una educación tiene calidad en la medida en que es completa, coherente y eficaz” (pp. 9-23).

En este sentido, "la eficacia permite transitar de una educación que atiende la cantidad a una que lo hace con calidad" (García, 1981, pp. 9-23). Por otra parte, De la Orden (1981) llegó a considerar que "la crisis de la educación era explicada como una crisis de calidad y este concepto se puso de moda en el ámbito educativo. En este mismo sentido, De la Orden comenta que, ante cualquier carencia o problema en la educación, la mala calidad se constituyó en la principal explicación causal y, por lo tanto, como consecuencia, el mejoramiento o logro de la calidad se convirtió en el objetivo prioritario para las autoridades educativas" (pp. 111-132).

Según Aguerrondo (2012), el concepto calidad, vinculado con la educación, surge "de la tecnología educativa y la ideología curricular, donde se asume la calidad de la educación bajo las premisas de eficiencia, y esta entendida como eficiencia escolar" (p. 572).

Otra característica importante del concepto de calidad aplicado a la educación es el hecho de que este puede servir de patrón de comparación para ajustar decisiones y reajustar procesos en el ámbito educativo de forma que optimizando los medios de que dispone sea capaz de brindar educación de calidad a toda la población (Aguerrondo, 2012, p. 572).

\section{La calidad de la educación: ejes para su definición y evaluación}

El concepto de ruralidad es de suma importancia ya que este se caracteriza por ubicarse en zonas rurales alejadas de las zonas urbanas y en las que se desarrolla diversas actividades, como la agricultura, la agropecuaria y la ganadería la cuales son fundamentales para su desarrollo, así mismo como la educación rural la cual juega un papel importante en estos espacios geográficos que en su mayoría no son atendidos, ni se crean políticas dignas para el desarrollo educativo en la ruralidad.

Así mismo, Páez, Fernández y Mayordomo (2000) expresan “la Educación rural es la columna vertebral del desarrollo rural, sin ella la absorción y la adopción de tecnología no será posible, la historia nos presenta evidentes ejemplos al respecto” (pp. 51-71). 


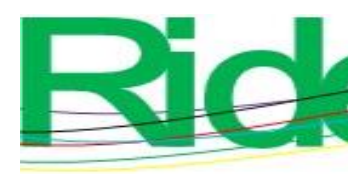

Revista Iberoamericana para la Investigación y el Desarrollo Educativo ISSN $2007-7467$

Por lo anterior resulta evidente que la educación rural es parte fundamental en toda sociedad y para el estado colombiano no es la excepción, que consiente a través de la educación se alcanza todos los diferentes ámbitos y para el desarrollo de todas las zonas, y que a través de ella se puede dar a conocer todos los aspectos tantos tecnológicos como científicos que están al alcance para el avance de la sociedad en todos sus aspecto.

El análisis de la calidad de la educación es un aspecto que se torna visible e importante en la actualidad. Al respecto, Blanco (2008) señala:

La calidad de la educación es una aspiración constante de los sistemas educativos compartida por el conjunto de la sociedad, y uno de los principales objetivos de las reformas educativas de los países de la región, lo que implica cierta relevancia, pertinencia y actualidad, que requiere ser reflexionada, pensada y debatida (p. 2008).

Por todo lo anteriormente expreso la percepción común que se tiene de lo rural es que está en oposición a lo urbano asimilando que este último a la vida en la ciudad bajo el paradigma de la industrialización y la modernización. Por lo anterior el concepto de lo rural, es la vida en el campo entendida como sinónimo de atraso, de tradición, de localismo.

\section{Educación comunitaria en el ámbito rural}

En la actualidad, de muchas maneras se ha venido haciendo referencia a lo rural, de ahí que se hayan convertido en habituales expresiones como vida rural, crédito rural, salud rural, pobreza rural, desarrollo rural y, desde luego, educación rural, esta última empleada como una categoría que se considera clarificada y comprendida por quienes la utilizan.

Sin embargo, la realidad demuestra que lo rural puede generar confusión en muchas personas, de ahí la necesidad de realizar un acercamiento a dicho término para intentar ofrecer pautas que permitan generar una definición más precisa. Al respecto, Castro y Reboratti (2008), aunque refiriéndose al contexto argentino, indican:

El concepto de ruralidad necesita de una revisión y dicha afirmación cabe plenamente para nuestro entorno, toda vez que, como en el anterior país, nuestro ideario "sigue utilizando una acepción de lo rural acuñada en Francia en el siglo XIX, cuyo criterio principal de diferenciación rural-urbana es la cantidad de habitantes por localidad (p. 15). 


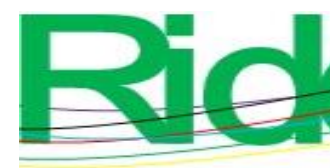

Revista Iberoamericana para la Investigación y el Desarrollo Educativo ISSN 2007 - 7467

\section{Entonces... ¿qué es lo rural?}

Se puede partir de la base que establece que lo rural es una construcción social; sin embargo, a la hora de precisar una definición se halla que no existe un consenso en torno a dicho término, aunque se puede decir que cualquier acercamiento teórico pasa por atender a lo diverso, pues existe una gran variedad de formas de expresar lo rural. En este sentido, Pérez (2001) opina que en "una nueva visión de lo rural no debe plantear la unidireccionalidad del cambio (de lo atrasado a lo moderno, de lo rural a lo urbano), sino considerar una serie de características que muestran la multidireccionalidad del proceso" (p. 24). Esto, lógicamente, significa un cambio drástico de visión frente a lo rural, lo que implica superar las concepciones dicotómicas frente a lo urbano para tener en cuenta a la heterogeneidad de lo rural, su dinamismo y sus características socioculturales, económicas y geográficas. En palabras de Itzcovich (2010), “el concepto territorio (no limitado a lo espacio-territorial) engloba, en gran parte, las realidades, procesos, dimensiones y situaciones que allí se desarrollan" (p. 28).

\section{La educación rural}

Según Lozano (2012), uno de los primeros estudios sobre educación rural realizado en el municipio Tabio (Cundinamarca) es el de Seibold (2014). Este autor encontró que las escuelas analizadas apenas lograban enseñar a un reducido número de niños los rudimentos de la escritura, la lectura y el uso de las cuatro operaciones aritméticas.

Por su parte, Guhl (1956) y Coll, Rosera, Mayordomo y Naranjo (2007) mencionan que "en estudios separados presentaron informes sobre la educación rural en los departamentos de Caldas y Nariño, respectivamente" (p. 21).

\section{Educación permanente del docente rural}

El análisis de la formación del docente rural y su incidencia en la calidad educativa de dicho ámbito es un campo apenas explorado; si bien se han concretado algunos estudios sobre la formación del docente rural — sea inicial o permanente—, su correlación con la calidad educativa es insipiente.

En Costa Rica, entre los años 2006 y 2007, Vargas (2014) realizó un estudio sobre "la labor docente y la formación de educadores rurales donde se buscaba explorar la labor de los docentes rurales en Costa Rica y analizar los planes de formación impartidos por las 


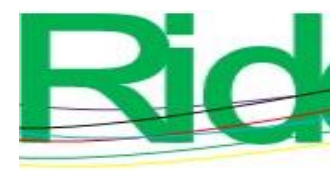

Revista Iberoamericana para la Investigación y el Desarrollo Educativo ISSN $2007-7467$

universidades públicas” (p. 28). Este trabajo intentó alinearse con lo señalado por el Instituto Nacional de Formación Docente (2007):

Procurar dar respuesta a requerimientos específicos de formación y atender particularidades de carácter permanente o temporal, personales y/o contextuales, con el propósito de garantizar la igualdad en el derecho a la educación y cumplir con las exigencias legales, técnicas y pedagógicas de los diferentes niveles educativos (p. 14).

Ese tipo de iniciativas resultan esenciales debido a que intentan lo siguiente:

Realizar aportes desde la especialidad en las diversas disciplinas de la Formación General y de la Específica, así como en los espacios de formación en la Práctica Profesional, diferenciando los aspectos comunes al trabajo docente y las particularidades que el contexto rural requiere tanto en la formación inicial como en la orientada (Instituto Nacional de Formación Docente, 2007, artículo 6).

En este mismo sentido, Brumat y Baca (2015), en una indagación desarrollada en algunas escuelas rurales de primaria de la provincia de Córdoba (Argentina), indican el trabajo realizado, el cual consistió es describir "algunas características de la práctica docente en contextos rurales describiendo condiciones de trabajo de los docentes, algunas notas referidas a su formación y a su práctica cotidiana" (p. 10).

Por otra parte, en lo que respecta a la formación continua, se destacan algunos esfuerzos realizados por algunas entidades para ofrecer algún tipo de acercamiento al ámbito rural, lo cual — como apuntan Brumat y Baca (2015) — ha resultado insuficiente:

En la década de los noventa, con la implementación de la Ley Federal de Educación, la Educación Rural había sido desatendida en términos generales y también en lo que respecta a la formación de docentes, siendo escasa o nula la referencia de formación específica para esta modalidad educativa (p. 13).

Esta realidad ha servido para que en diversos países de Latinoamérica se adopten iniciativas para atender algunos problemas percibidos en dicho ámbito:

A partir de nuevas propuestas de formación de los maestros y maestras (...) en la actualidad los países latinoamericanos han desarrollado una serie de programas de formación en posgrado como medios estratégicos para incrementar el capital social y el bienestar de la comunidad, con posibilidades 


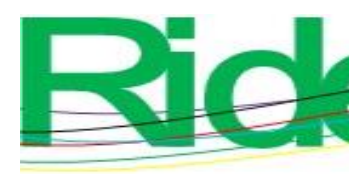

\section{Revista Iberoamericana para la Investigación y el Desarrollo Educativo ISSN 2007 - 7467}

de aportar significativamente a la cultura, el arte y la ciencia (Romero, 2012, p. 17).

El propósito ha sido impulsar en el docente una conciencia para plantear y desarrollar estrategias de formación permanente, necesidad indispensable en los tiempos actuales de exigencia, evaluación y vigilancia (Lorenzatti, Brumat y Beinotti, 2014; Ramírez, 2014; Zamora, 2015), ya que algunos estudios — como el realizado por Cruz y Juárez (2018) en México y El Salvador - muestran que "los maestros no son formados ni capacitados para enfrentarse a las particularidades de las aulas rurales multigrado" (p. 40).

\section{Concepto de tecnologías de la información y comunicación}

Existen múltiples definiciones de las TIC. Aun así, Cabero (2015) señala:

En líneas generales, podríamos decir que las tecnologías de la información y comunicación son las que giran en torno a tres medios básicos: la informática, la microelectrónica y las telecomunicaciones; pero giran no solo de forma aislada, sino lo que es más significativo, de manera interactiva e interconexionadas, lo que permite conseguir nuevas realidades comunicativas (p. 221).

En este mismo sentido, Beck (1998) considera que "las TIC encuentran su papel como una especialización dentro del ámbito de la didáctica y de otras ciencias aplicadas de la educación, refiriéndose especialmente al diseño, desarrollo y aplicación de recursos en procesos educativos" (p. 67), mientras que Beck (1998) menciona que "el impacto de las TIC no se refleja únicamente en un individuo, grupo, sector o país, sino que se extiende al conjunto de las sociedades del planeta" (p. 78).

\section{El impacto de las TIC en la educación}

Según la Unesco, las TIC son "aquellos medios y servicios que permiten recopilar, almacenar y transmitir información con medios electrónicos” (Unesco, 2013, p. 10). A esta definición, el referido organismo añade:

Estas TIC han tenido distintos hitos históricos en su desarrollo e implantación social, destacando entre los últimos (aunque ni mucho menos los únicos, como veremos) los acontecidos durante la denominada "revolución digital", especialmente los que hacen referencia a la difusión de los ordenadores 


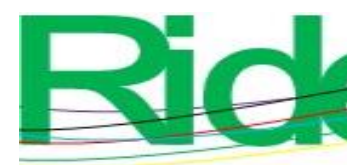

\section{Revista Iberoamericana para la Investigación y el Desarrollo Educativo ISSN 2007 - 7467}

personales y, más recientemente, de internet. En cualquier caso, ha de tenerse presente que la tecnología ha de concebirse más bien como un continuo que va desde los libros o las pizarras, pasando por la radio o el video, hasta los elementos informáticos o las aplicaciones de internet más avanzadas (Unesco, 2012, p. 14).

En este sentido, Majó y Marqués (2001) explican:

Esta emergente sociedad de la información, impulsada por un vertiginoso avance científico en un marco socioeconómico neoliberal-globalizador y sustentada por el uso generalizado de las potentes y versátiles tecnologías de la información y la comunicación, conlleva cambios que alcanzan todos los ámbitos de la actividad humana (p. 738).

Asimismo, Aviram (2002) identifica tres posibles reacciones de los centros docentes para adaptarse a las TIC y al nuevo contexto cultural:

- Escenario tecnócrata. Las escuelas se adaptan realizando simplemente pequeños ajustes: en primer lugar la introducción de la "alfabetización digital" de los estudiantes en el currículo para que utilicen las TIC como instrumento para mejorar la productividad en el proceso de la información y luego progresivamente la utilización de las TIC como fuente de información y proveedor de materiales didácticos.

- Escenario reformista. Se dan los tres niveles de integración de las TIC que apunta Beltrán (2003) los dos anteriores (aprender SOBRE las TIC y aprender de las TIC) y además se introducen en las prácticas docentes nuevos métodos de enseñanza/aprendizaje constructivistas que contemplan el uso de las TIC como instrumento cognitivo (aprender CON las TIC) y para la realización de actividades interdisciplinarias y colaborativas (Beltrán, 2003).

- Escenario holístico: Los centros llevan a cabo una profunda reestructuración de todos sus elementos. De igual forma, Morín (2007) plantea que "la escuela y el sistema educativo no solamente tienen que enseñar las tecnologías, sino que estas aparte de producir unos cambios en la escuela generan un cambio en el entorno" (p. 470). 


\section{Metodología}

Debido a la naturaleza de esta investigación, se ha decidido seguir predominantemente un enfoque cuantitativo con un diseño descriptivo y correlacional, aunque vale acotar que luego de dar respuesta a cada una de las preguntas de investigación, así como a la hipótesis formulada, se tomaron en cuenta algunos aspectos de índole cualitativa. Esta amalgama de enfoques tiene la ventaja de ofrecer mayor profundidad en la información recabada, así como dispersión, riqueza interpretativa y contextualización del entorno. Por lo anterior, el diseño metodológico - en principio- consistió en una investigación teórico-empírica, ya que al ser de índole educativa se estableció la correlación de sus variables: formación docente en el ámbito rural, uso de las TIC como modelo pedagógico y calidad educativa.

\section{Tipo de estudio}

El diseño de la investigación consistió en un estudio de caso, único e inclusivo, dentro del cual se combinaron características a partir de muestras. Esta investigación cualitativa como cualquier otra - está sometida a un proceso que incluye seis fases (Saad, 2007), las cuales se presentan a continuación:

- Están comprometidas con una perspectiva naturalista y una comprensión interpretativa de la experiencia humana.

- El campo de la investigación cualitativa es inherentemente político y se perfila a través de múltiples posiciones éticas y políticas (Paniagua, 2003 p. 30).

- En este caso, los profesores como sujetos importantes y protagónicos.

- Son tomados como unidades de análisis, incluidos en el caso general.

- El objeto de estudio se toma en sus condiciones naturales.

- No son creadas situaciones experimentales ni artificiales, sino que los procesos son abarcados tal cual se presentan en su ambiente cotidiano. 


\section{Técnicas para la recolección de datos}

Las técnicas e instrumentos son los elementos que permiten recopilar la información adecuada y necesaria para realizar cualquier tipo de investigación. Estos incluyen principalmente el análisis de encuestas, cuestionarios y documentos oficiales, así como de textos de autores que hayan desarrollado alguna temática acerca del asunto central. En concreto, la revisión se enfoca en determinar qué tanto los docentes seleccionados utilizan y dominan las TIC dentro de los procesos de enseñanza-aprendizaje en ámbitos rurales de la región del Tequendama (Colombia).

\section{Muestra}

La población total estaba constituida por 121 docentes rurales de tres instituciones educativas diferentes, aunque del mismo municipio, de los cuales 57 orientan los procesos en primaria, y 64 en secundaria (básica y media). De estos se tomaron como muestra por conveniencia 90 maestros y maestras que corresponde a un $74 \%$ de la población total de profesores que laboraban en el año lectivo 2019.

Tabla 1. Población

\begin{tabular}{|l|c|c|c|c|c|}
\hline \multicolumn{1}{|c|}{ Docentes } & $\begin{array}{c}\text { IED San } \\
\text { Antonio del } \\
\text { Tequendama }\end{array}$ & $\begin{array}{c}\text { IED } \\
\text { mariano } \\
\text { Santamaría }\end{array}$ & $\begin{array}{c}\text { IED } \\
\text { Pradilla }\end{array}$ & Total & $\begin{array}{c}\text { Tamaño } \\
\text { de la } \\
\text { Muestra }\end{array}$ \\
\hline Primaria & 18 & 21 & 18 & 57 & 40 \\
\hline Secundaria & 17 & 27 & 20 & 64 & 50 \\
\hline \multicolumn{6}{|c|}{ Total } \\
\hline
\end{tabular}

Fuente: Elaboración propia

\section{Descripción del instrumento}

Antes que nada, es importante decir que a continuación se muestran los datos obtenidos y como resultado del trabajo de investigación que se expuso en los apartados anteriores y que mantiene relación con la premisa investigativa que fue guía durante la aplicación de la encuesta sobre la formación del docente rural y los aspectos pedagógicos en este ámbito, así como el uso de las TIC en relación con la calidad educativa de la educación ya antes descritas rural. 


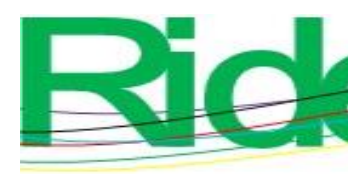

Revista Iberoamericana para la Investigación y el Desarrollo Educativo ISSN 2007 - 7467

El instrumento aplicado en la muestra se planteó en el cuestionario lo referente a la actitud, uso y dominio de las TIC; Se dividió en los siguientes campos: I. Formación académica, II. Formación pedagógica, III. Estrategias metodológicas para utilizar las TIC en el aula y IV. Competencias docentes en el uso de las TIC.

\section{Procesamiento de datos}

En la encuesta aplicada se establecieron 27 preguntas en las que se relacionaron la formación del docente rural, el conocimiento y uso de las TIC en el aula en los procesos pedagógicos de cada docente. Este instrumento de naturaleza cuantitativa sirvió para recabar información que luego fue analizada de forma cualitativa.

\section{Discusión}

A continuación, en la figura 1 y en las tablas 2 y 3 se ofrece la información recabada en torno a la edad de los docentes, sus años de experiencia y sus niveles de formación, lo cual sirve para intentar dar respuesta a la siguiente pregunta: ¿qué tan importantes son la experiencia docente y la formación en el uso y manejo de las TIC en los procesos de enseñanza-aprendizaje en el nivel educativo de secundaria en una zona rural?

En la figura 1 se observa que 23 profesores que corresponde a un $26 \%$ del total de doncentes encuestados se hallan en el rango de edad de 20 y 30 años, lo que significa que están iniciando su carrera profesional y que deben asumir nuevos retos de mejora educativa continua. Asimismo, 46 docentes correspondiente a un 51\% están en un rango de entre 31 y 40 años de edad, lo cual indica que se encuentran en una media productiva en la cual su trayectoria académica en formación por competencias en el uso y manejo de las TIC será fundamental para potenciar su práctica docente. Igualmente, 18 profesores un $20 \%$ se ubican en el rango de entre 41 y 50 años de edad; estos se encuentran en una edad productiva donde su compromiso será fortalecer cada una de las estrategias de aprendizaje centrada en competencias docentes para el nivel que les corresponda. Por último, solo 3 con un porcentaje del 3\% de profesores están en el rango de entre 51 y 60 años de edad, los cuales piensan más en su retiro que en su formación académica. 
Figura 1. Rangos de edad de los docentes participantes

\section{Rangos de edad}

40

20

0

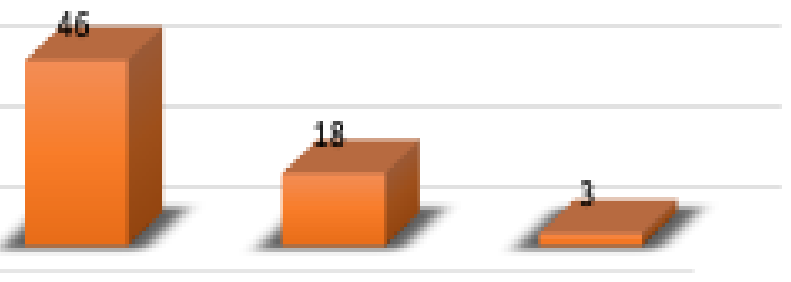

$20-30 \quad 31-40 \quad 41-50 \quad 51-60$

Fuente: Elaboración propia

En la tabla 2 se observa que solo $3 \%$ de los docentes tienen entre 0 y 5 años de experiencia docente, lo cual demuestra la juventud y la falta de experiencia para desarrollar diferentes procesos y estrategias de aprendizaje, aunque también podría indicar un nivel alto de familiaridad con las TIC como para aplicarlas en el aula. Los porcentajes más altos se encuentran en los rangos 6-10 (31\%) y 11-15 (26\%) años de experiencia.

Tabla 2. Años de experiencia docente

\begin{tabular}{|c|c|c|}
\hline $\begin{array}{c}\text { Años de } \\
\text { docencia }\end{array}$ & N. $^{\circ}$ & $\%$ \\
\hline $0-5$ & 3 & $3 \%$ \\
\hline $6-10$ & 28 & $31 \%$ \\
\hline $11-15$ & 23 & $26 \%$ \\
\hline $16-20$ & 17 & $19 \%$ \\
\hline $21-25$ & 12 & $13 \%$ \\
\hline 26 o más & 7 & $8 \%$ \\
\hline TOTAL & 90 & $\begin{array}{c}100 \\
\%\end{array}$ \\
\hline
\end{tabular}

Fuente: Elaboración propia

En lo que respecta al último nivel de formación con un $49 \%$ que representa a 44 de los docentes son licenciados, $32 \%$ que representa a 29 profesores son especialistas, mientras que 17 docentes que representa al $19 \%$ tienen el grado de maestro y ninguno tiene doctorado (tabla 3). 


\section{Revista Iberoamericana para la Investigación y el Desarrollo Educativo ISSN 2007 - 7467}

Tabla 3. Ultimo nivel de formación

\begin{tabular}{|c|c|c|}
\hline Último nivel de estudios $^{\circ}$ & N. $^{\circ}$ & $\%$ \\
\hline Licenciatura & 44 & $49 \%$ \\
\hline Especialización & 29 & $32 \%$ \\
\hline Maestría & 17 & $19 \%$ \\
\hline Doctorado & 0 & $0 \%$ \\
\hline TOTAL & 90 & $100 \%$ \\
\hline
\end{tabular}

Fuente: Elaboración propia

Ahora bien, a continuación, en las figuras de la 2 a la 5 se enseña información con la cual se procura dar respuesta a la siguiente pregunta: ¿cuál es el nivel de conocimiento por parte de los docentes sobre el uso y dominio de las TIC, y cómo esto impacta en la secundaria de una zona rural?

En la figura 2 se observa que 57 docentes que representan al $63 \%$ del total de la muestra usan frecuentemente recursos tecnológicos en el aula, mientras que 23 docentes correspondiente al $26 \%$ a veces los emplean, ningún profesor dijo que nunca los utilizaba, aunque vale acotar que para 10 docentes correspondiente al $11 \%$ consideran que esta pregunta no aplicaba.

Figura 2. Utilización de medios tecnológicos en el aula

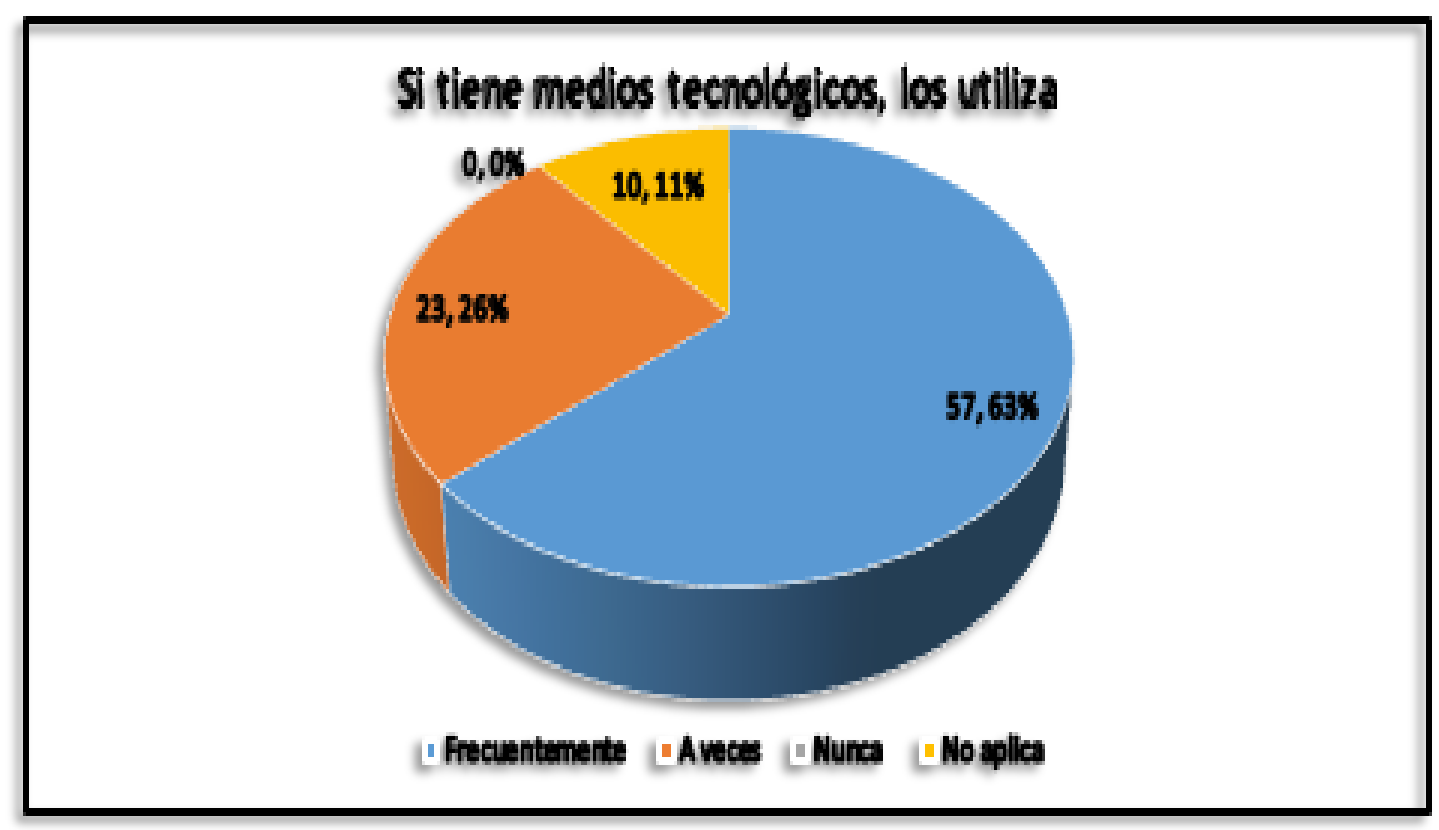

Fuente: Elaboración propia 


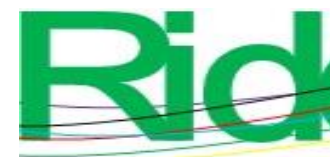

\section{Revista Iberoamericana para la Investigación y el Desarrollo Educativo ISSN 2007 - 7467}

En la figura 3 se aprecia que 45 que corresponde al $50 \%$ de los docentes nunca han tenido formación en el uso de las TIC para la educación rural, 32 con un porcentaje del 36\% de los profesores dicen que algunas veces y 13 equivalente al $14 \%$ de los docentes encuestados opinan que raras veces.

Figura 3. Las TIC y la educación rural

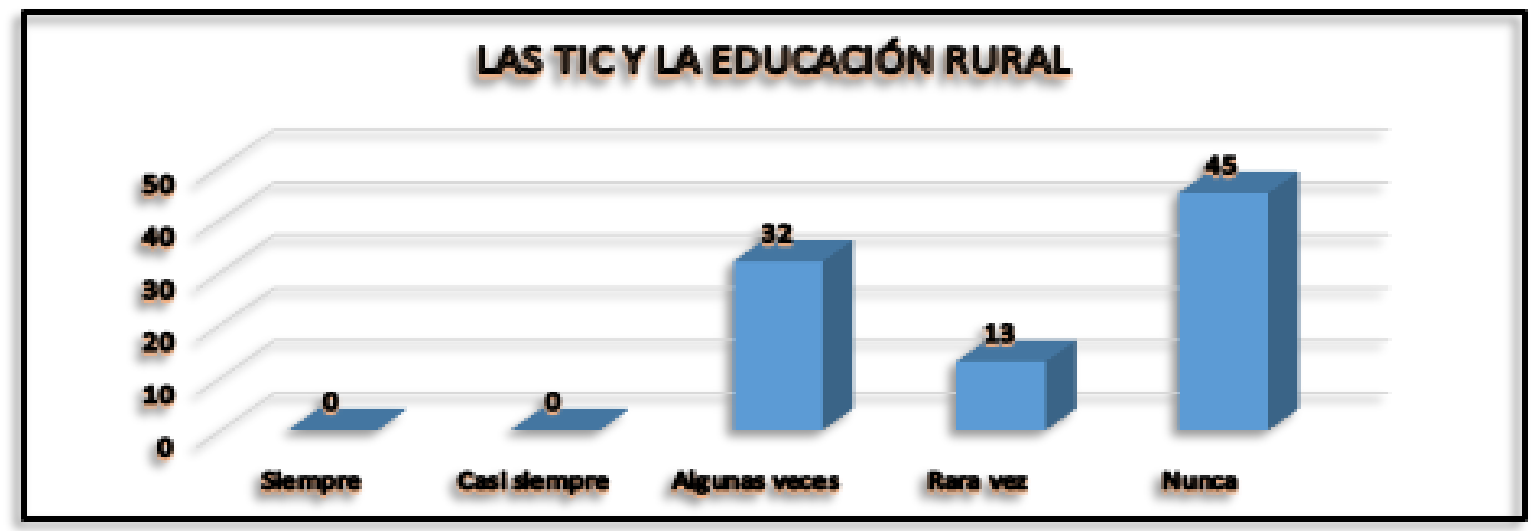

Fuente: Elaboración propia

Sobre el uso de plataformas educativas, se puede indicar que 43 de los docentes que corresponde al $48 \%$ de los docentes nunca las usan, mientras que 21 docentes que equivale al $23 \%$ tres veces a la semana, además de que que 15 profesores que corresponde al $17 \%$ las usan una vez a la semana, 7 docentes con $8 \%$ rara vez a la semana y 4 profesores con un $4 \%$ dos veces a la semana (figura 4 ).

Figura 4. Frecuencia de uso de plataformas educativas.

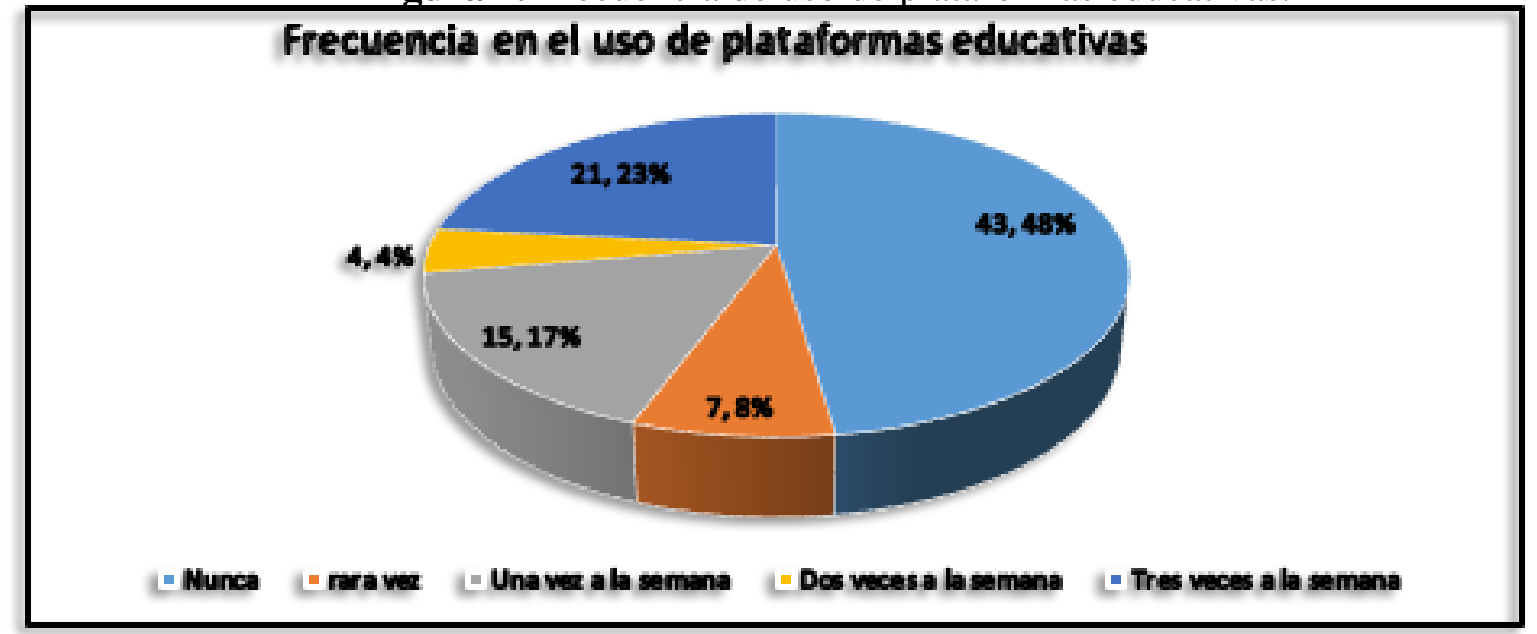

Fuente: Elaboración propia 

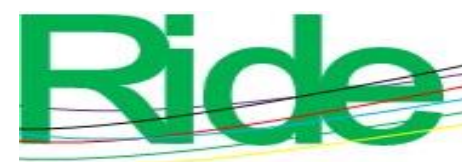

Revista Iberoamericana para la Investigación y el Desarrollo Educativo

ISSN $2007-7467$

Ahora se hace especificación de algunas herramientas tecnológicas particulares y la frecuencia con la que los docentes la usan, iniciando por la web del docente; en este caso el $53 \%$ que corresponde a 48 profesores de los encuestados dicen que nunca las ha usado, mientras que 9 profesores que corresponde al 10\% rara vez, una vez a la semana lo usan 19 maestros y maestras equivalente al $21 \%$, mientras que 5 docentes la usan dos veces a la semana que equivale al 6\% del total de docentes encuestadoas y tres veces por semana 9 docentes, es decir el 10\% (figura 5).

Figura 5. Frecuencia de uso de la web docente

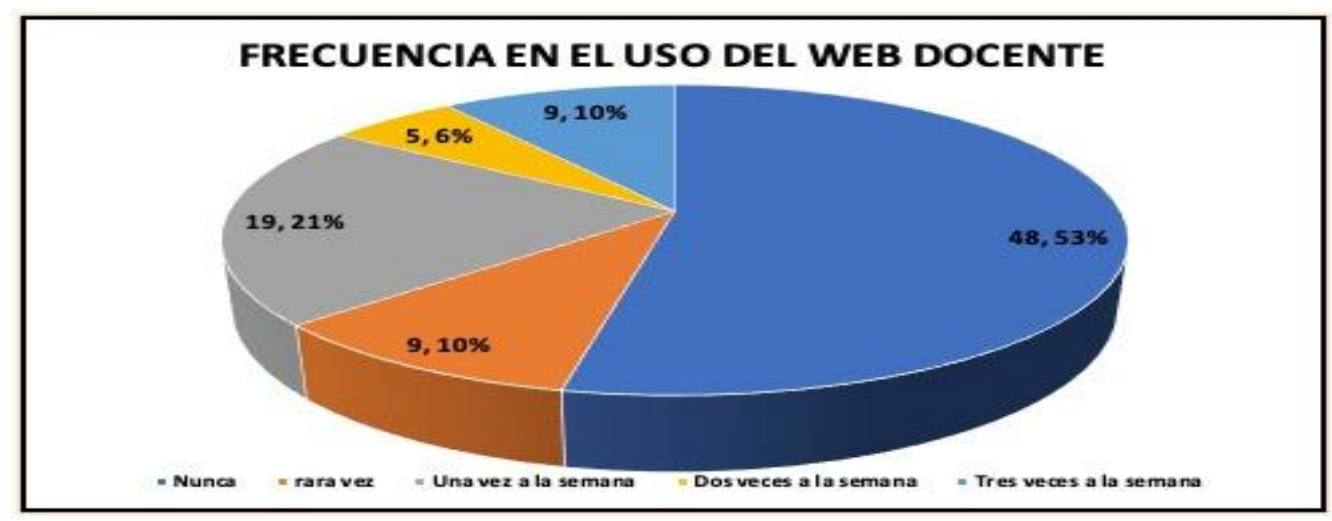

Fuente: Elaboración propia

Por otra parte, y para dar respuesta a la siguiente interrogante (¿qué tanto usan y dominan las TIC como estrategias pedagógicas y metodológicas para mejorar cada uno de los procesos de enseñanza-aprendizaje los docentes de la secundaria de una zona rural?), a continuación en las figuras 6-10 se muestra la información recabada.

En cuanto a la evaluación y uso de las TIC y la manera como inciden en el proceso enseñanza-aprendizaje, 39 docentes indican que algunas veces son conscientes de dicho impacto, mientras que 18 opinan que siempre conocen dicha incidencia. 

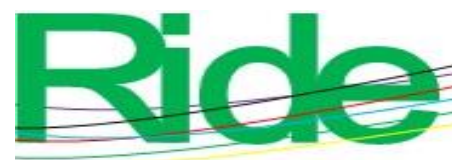

Revista Iberoamericana para la Investigación y el Desarrollo Educativo ISSN 2007 - 7467

Figura 6. La evaluación en el proceso de enseñanza-aprendizaje

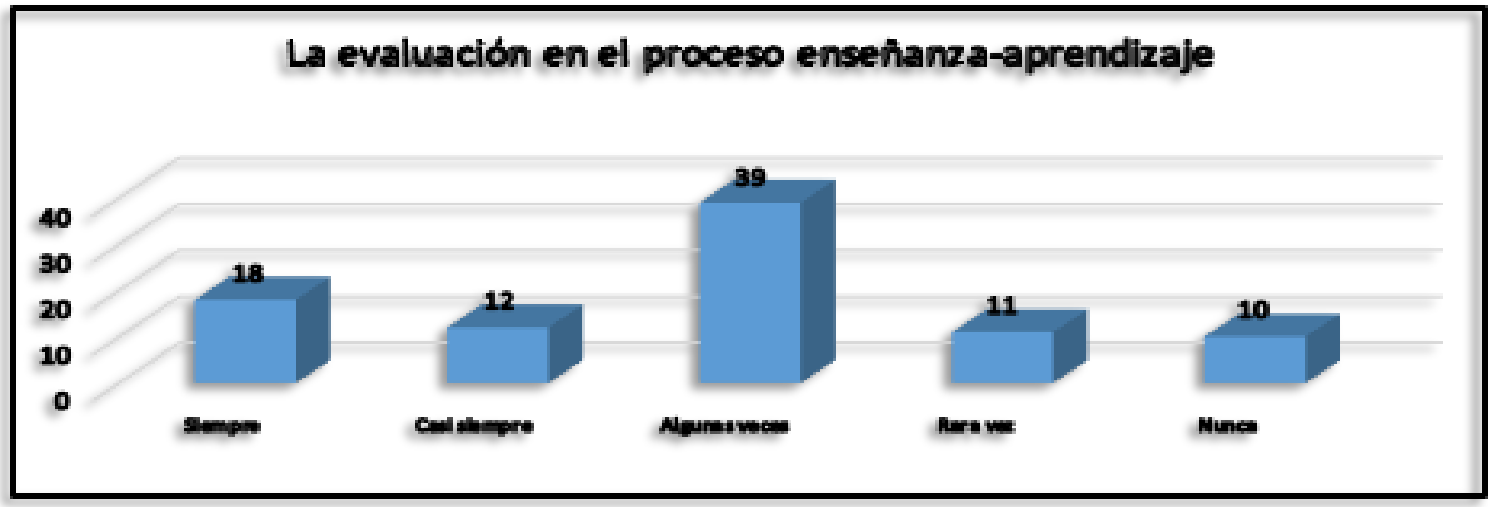

Fuente: Elaboración propia

En lo concerniente a la selección y diseño de instrumentos para la evaluación del aprendizaje mediante las TIC, 30 profesores manifestaron que raras veces sabían cómo hacerlo, mientras que 28 docentes algunas veces sabían la manera de hacerlo.

Figura 7. Selección y diseño de instrumentos y recursos para la evaluación del aprendizaje

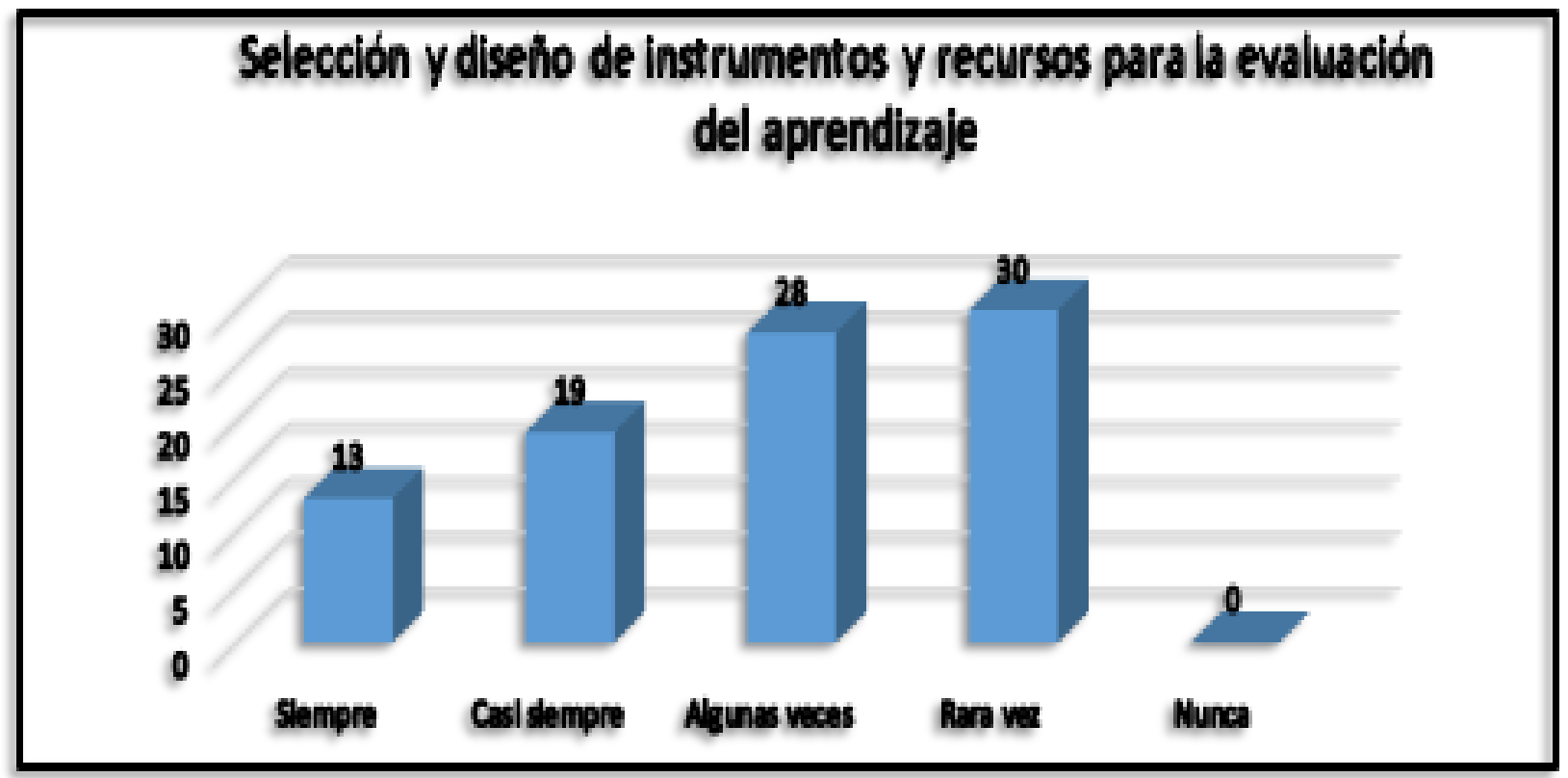

Fuente: Elaboración propia

Sobre la evaluación y selección de materiales educativos en relación con su incidencia en el proceso de enseñanza-aprendizaje mediados por las TIC, 47 profesores consideran que algunas veces tienen ese conocimiento, mientras que 23 siempre lo tienen. 


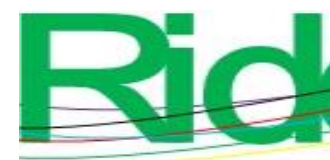

Revista Iberoamericana para la Investigación y el Desarrollo Educativo ISSN 2007 - 7467

Figura 8. Evaluación y selección de materiales educativos

\section{Evaluación y selección de materiales educativos}

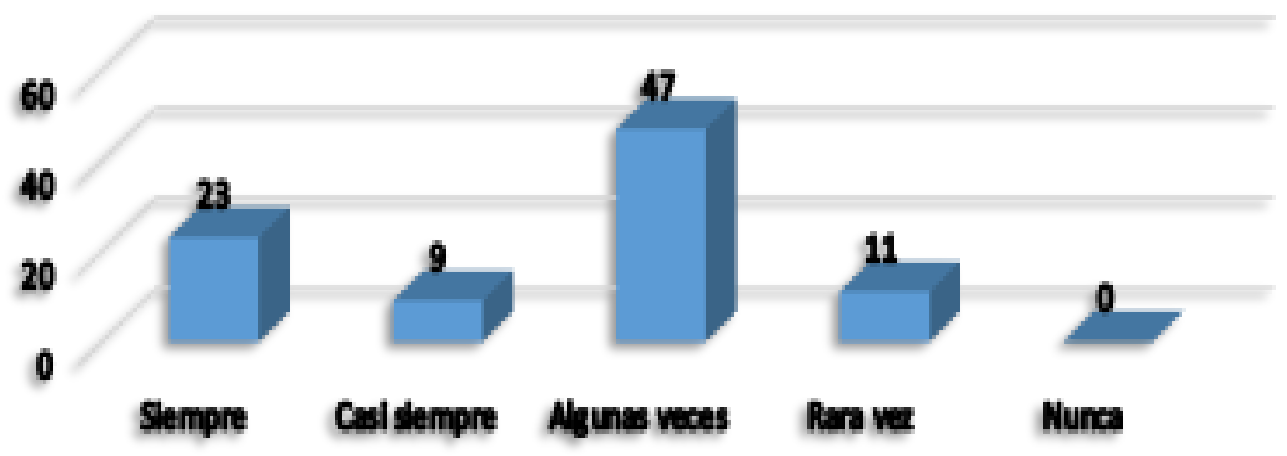

Fuente: Elaboración propia

Con respecto al uso de los medios tecnológicos y su influencia en el aprendizaje, 47 profesores indican que las TIC han contribuido a mejorar la impartición de las clases, mientras que a 12 docentes les parece irrelevante.

Figura 9. Contribución de los medios tecnológicos para mejorar la impartición de las clases

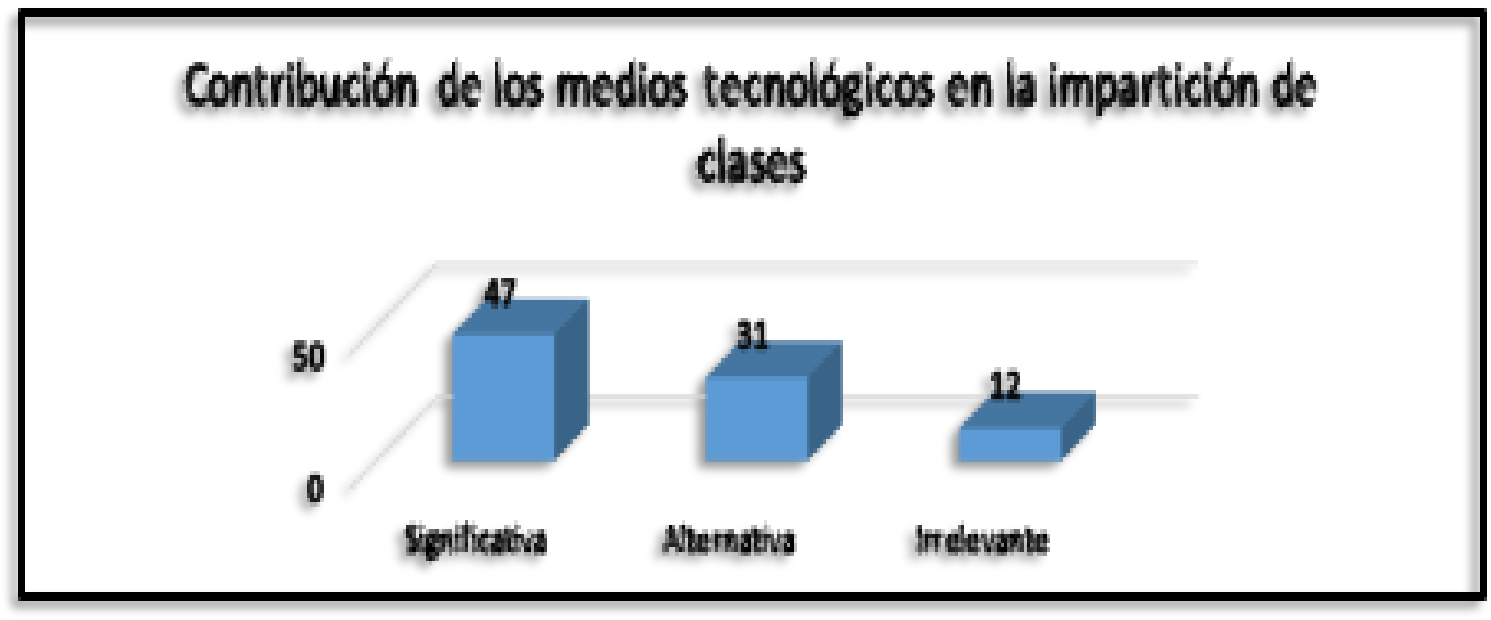

Fuente: Elaboración propia

Sobre su dominio y manejo de las TIC, 57 profesores que corresponde al $63 \%$ del total de los docentes encuestados considera que es bueno, mientras que 33 de los profesores encuestados que equivale al $37 \%$ cree que es suficiente (figura 10). 


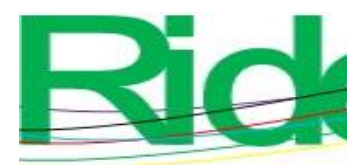

\section{Revista Iberoamericana para la Investigación y el Desarrollo Educativo ISSN 2007 - 7467}

Figura 10. Dominio de habilidades que tiene en el manejo de las TIC.

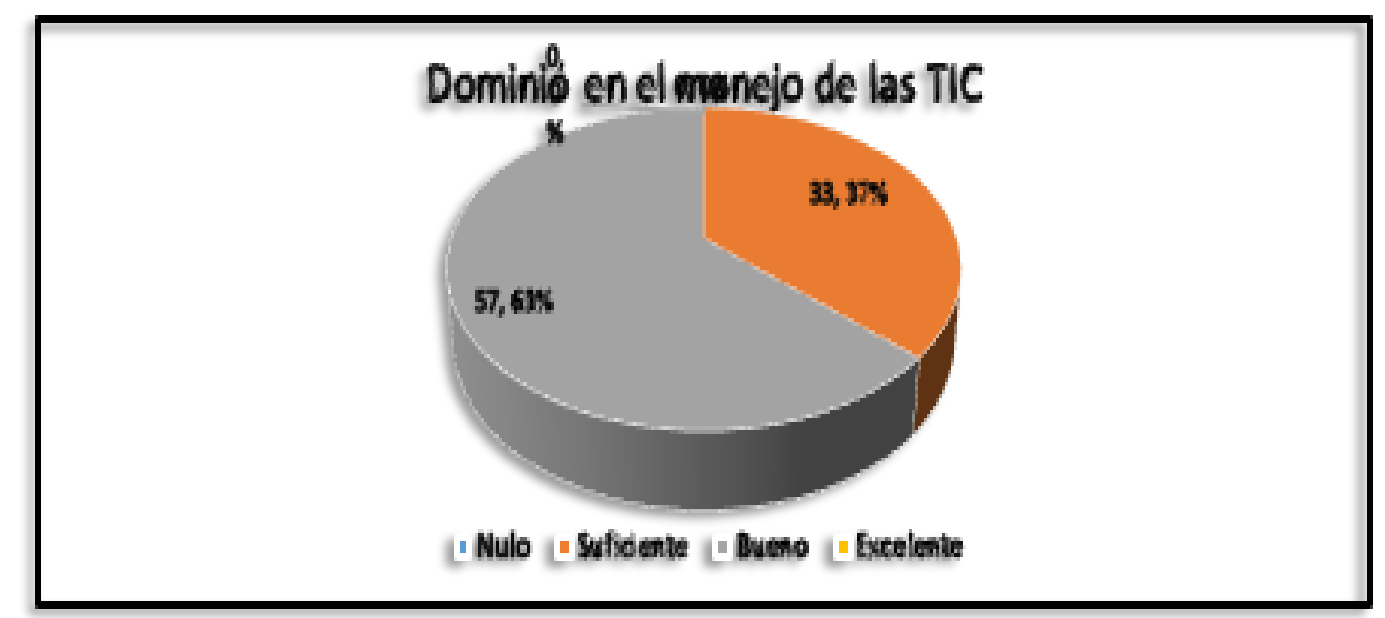

Fuente: Elaboración propia

Finalmente, y para responder a la pregunta ¿cuál ha sido el efecto motivador del uso y manejo de las TIC como estrategia pedagógica y metodológica en cada uno de los procesos de enseñanza aprendizaje dentro del aula?, se ofrece la información que se enseña en las tablas 4 y 5, así como en la figura 11.

En tal sentido, en la tabla 4 — de forma general — se puede indicar que 84 profesores encuestados equivalente a un $94 \%$ de los docentes encuestados consideran que es un factor determinante en el aprendizaje de los estudiantes; por otra parte 45 profesores encuestados equivalente a un $50 \%$ de los docentes encuestados consideran que es una moda dada la era tecnológica en que vivimos; así mismo 78 profesores encuestados equivalente a un $87 \%$ de los docentes encuestados consideran que es una herramienta de apoyo alternativa para la enseñanza de los diversos contenidos; mientras que 87 profesores encuestados equivalente a un $97 \%$ de los docentes encuestados consideran que es una herramienta totalmente prescindible; por otro lado 25 profesores encuestados equivalente a un $28 \%$ de los docentes encuestados consideran que Es una alternativa que no necesariamente influye en los aprendizaje de los estudiantes; otro elemento considerado por los docentes en esta encuesta es que 25 profesores encuestados equivalente a un $88 \%$ consideran que Es un recurso importante para la mejore de los procesos de enseñanza aprendizaje; así como también 84 docentes de un $93 \%$ de su totalidad manifestaron que Facilita el trabajo en grupo y colaboración con sus alumnos. 
Tabla 4. Uso de las TIC como herramienta pedagógica

\begin{tabular}{|c|c|c|}
\hline $\begin{array}{c}\text { CONSIDERA QUE EL USO DE LAS TIC EN CLASE } \\
\text { (PUEDE SELECCIONAR MÁS DE UNA OPCIÓN): }\end{array}$ & CANT. & $\%$ \\
\hline $\begin{array}{c}\text { Es un factor determinante en el aprendizaje de los } \\
\text { estudiantes }\end{array}$ & 85 & $94 \%$ \\
\hline $\begin{array}{c}\text { Es una moda dada la era tecnológica en que vivimos } \\
\text { Es una herramienta de apoyo alternativa para la enseñanza } \\
\text { de losersos contenidos }\end{array}$ & 78 & $50 \%$ \\
\hline $\begin{array}{c}\text { Es una herramienta totalmente prescindible } \\
\text { aprendizaje de los estudiantes }\end{array}$ & 87 \\
\hline $\begin{array}{c}\text { Es una alternativa que no necesariamente influye en los } \\
\text { enseñanza aprendizaje }\end{array}$ & 25 & $28 \%$ \\
\hline Promueve el interés y motivación de sus alumnos & 88 & $98 \%$ \\
\hline Facilita el trabajo en grupo y colaboración con sus alumnos & 84 & $93 \%$ \\
\hline TOTAL DE DOCENTES ENCUESTADOS & 90 & \\
\hline
\end{tabular}

Fuente: Elaboración propia.

Por otra parte, en la tabla 5 se aprecia que $97 \%$ de los consultados maneja Word, 30 \% Excel y ninguno el pizarrón (otros indicaron que Hot Potatoes, Prezzi, etc.).

Tabla 5. Software empleado como apoyo para desarrollar las clases

\begin{tabular}{|c|c|c|}
\hline $\begin{array}{c}\text { SOFTWARE QUE EMPLEA COMO APOYO PARA } \\
\text { DESARROLLAR SU CLASE }\end{array}$ & CANT. & $\%$ \\
\hline Word $^{\mathrm{TM}}$ & 87 & $97 \%$ \\
\hline ExcelTM $^{\mathrm{TM}}$ & 27 & $30 \%$ \\
\hline Otro & 0 & $0 \%$ \\
\hline Software asociado al pizarrón electrónico & 20 & $22 \%$ \\
\hline TOTAL DE DOCENTES ENCUESTADOS & 90 & \multicolumn{1}{|c}{}
\end{tabular}

Fuente: Elaboración propia

Asimismo, vale comentar que 38 docentes encuestados que equivale a un $42 \%$ consideran que son insuficiente los recursos informáticos con que cuenta la institución donde laboran; miestras que un alto porcentaje que corresponde al 52\% correspondiente a 47 profesores manifestaron que no tienen los recursos tecnológicos para llevar a cabo su labor docente, y por último 5 docentes que corresponde al $6 \%$ de los profesores cree que los recursos informáticos de su institución son suficientes. 


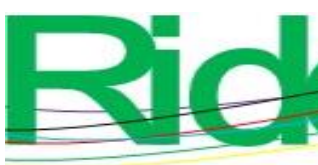

Revista Iberoamericana para la Investigación y el Desarrollo Educativo ISSN 2007 - 7467

Figura 11. Recursos informáticos que tiene su institución y los estudiantes

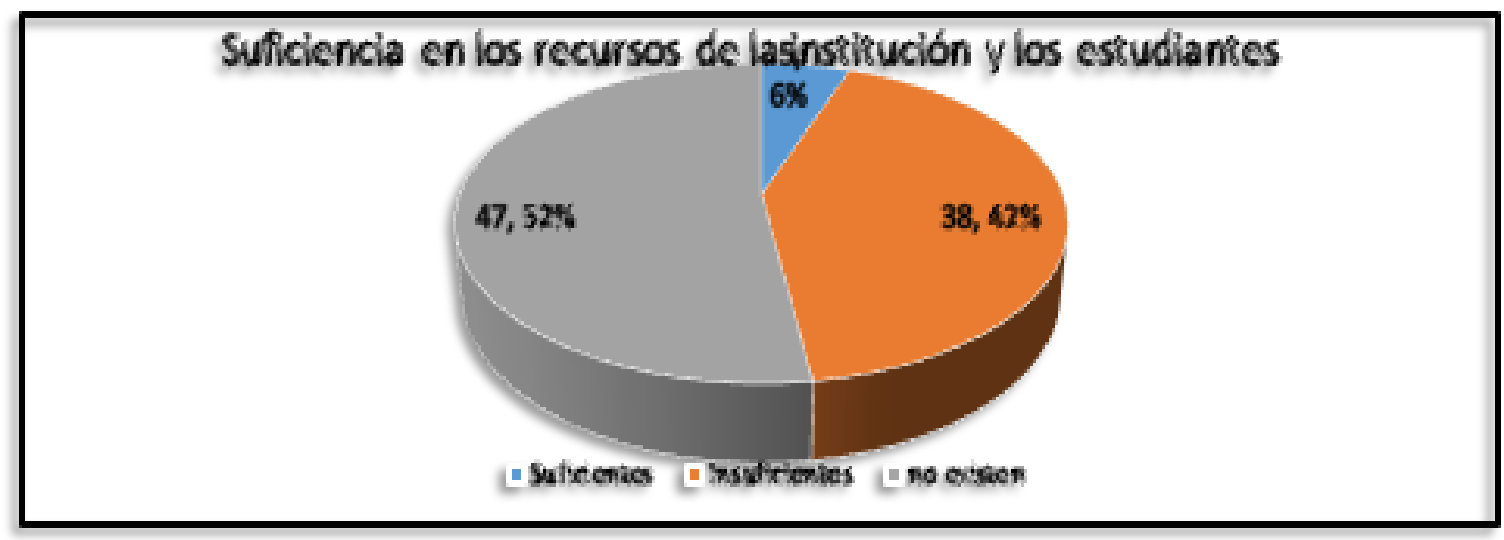

Fuente: Elaboración propia

\section{Respuesta a la pregunta principal}

Para dar respuesta a la pregunta central de este trabajo (¿cómo favorecer la formación de los docentes mediante el uso de las TIC en el contexto rural de la región del Tequendama — departamento de Cundinamarca, Colombia - para mejorar la calidad educativa en dicha comunidad y en otras zonas?), hay que tener en cuenta que en la actualidad las TIC desempeñan un papel importante en la educación en general y en la formación en la escuela en particular. Sin embargo, diferentes situaciones y factores han provocado que dichas tecnologías no hayan tenido el impacto esperado en los procesos de enseñanza-aprendizaje. Se debe recordar que la función docente en cualquier nivel educativo es impactante, esencial y preponderante, de ahí que sea necesario que los maestros cuenten con la formación suficiente para encarar la compleja tarea de promover el conocimiento en niños, adolescentes y jóvenes que cada vez están más rodeados de las nuevas tecnologías.

En ese sentido, es de obligatorio cumplimento que los docentes se preparen y continúen su formación en torno al uso de esas herramientas para mejorar la calidad educativa, en especial en ámbitos rurales. Para ello, lógicamente, resulta imperativo que los maestros, así como los estudiantes cuenten con los diversos medios electrónicos para generar las diversas competencias profesionales.

Sin embargo, también cabe señalar que en el presente trabajo se ha evidenciado que los docentes no han sido formados para el trabajo en zonas rurales, ambientes en los cuales se presentan particularidades y necesidades muy distintas a las de las zonas urbanas. Esto, en definitiva, desmejora la calidad educativa de esos lugares y, en consecuencia, profundiza la 

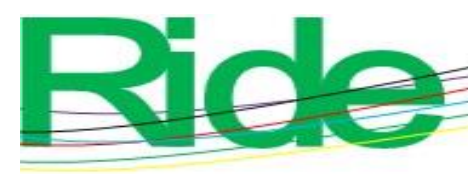

Revista Iberoamericana para la Investigación y el Desarrollo Educativo ISSN 2007 - 7467

desigualdad histórica promovida por políticas estatales que se han mantenido a lo largo del tiempo.

Esto último se puede afirmar porque ni el propio Estado se ha preocupado realmente por retomar la figura del docente rural ni por darle el lugar y la posibilidad de integrarlo al proceso de reforma educativa.

En definitiva, no basta solo con cursos o diplomados estériles que — para cumplir con la norma - obliguen al docente a tomarlos, sino que se deben establecer directrices en las universidades que apunten a formar futuros docentes capaces de enfrentarse a un contexto tan específico como el rural.

\section{Conclusiones}

Como ya se indicó en el apartado anterior, los datos obtenidos permiten sustentar lo que inicialmente se planteó con respecto al uso y manejo de las TIC en los docentes de las instituciones educativas departamentales del municipio San Antonio del Tequendama (Cundinamarca, Colombia) en cuanto a que dicha formación ha sido insuficiente como aporte y apoyo para la mejora de la calidad educativa en la ruralidad colombiana, específicamente en la mencionada región.

Los hallazgos encontrados dejan en evidencia que los docentes no han tenido ningún tipo de formación para la ruralidad, ni inicial ni continua, aunque se encuentren desempeñando su labor pedagógica en tales zonas. De hecho, aunque desde el Ministerio de Educación Nacional han sido emitidas propuestas pedagógicas flexibles para la ruralidad, la realidad demuestra que estas no se implementan en las instituciones incluidas en esta investigación.

En cuanto a las TIC, se debe decir que esos medios tecnológicos son usados por los docentes más para fines particulares y personales que pedagógicos, por lo que no han tenido el impacto esperado dentro de los procesos de enseñanza-aprendizaje. Esta situación es similar a la vivida por los alumnos, pues emplean dichos recursos principalmente con fines recreativos (juegos, redes sociales), y no tanto con propósitos académicos. Es decir, pareciera que el uso de los dispositivos electrónicos y sus redes sociales no solo está entorpeciendo el proceso de enseñanza, sino que también está convirtiéndose en una problemática para el manejo del aula. 


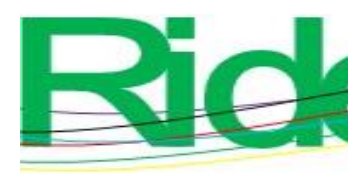

Revista Iberoamericana para la Investigación y el Desarrollo Educativo ISSN $2007-7467$

Sobre este asunto, preocupa saber que los profesores desconocen - y por eso no aprovechan - las infinitas posibilidades que ofrece la Web para promover el trabajo colaborativo. En otras palabras, el enfoque no debe recaer en luchar por prohibir el uso de esos dispositivos, sino en encontrar la manera de incorporarlos a los procesos educativos.

Por eso, los resultados conseguidos en este trabajo invitan a promover un programa que puede estar dividido en unidades didácticas, las cuales se pueden desarrollar de forma virtual mediante el uso de la página web de cada institución. En ese espacio, el docente encontraría propuestas novedosas y atractivas para que implemente con el alumno, de modo que pueda fomentar los conocimientos utilizando diversas herramientas y recursos tecnológicos para que el estudiante construya su propio conocimiento y adquiera las competencias necesarias.

Lógicamente, se debe prever que todo programa planteado a diversas personas puede resultar ineficaz; sin embargo, se debe decir que dicha ineficacia no se debe al programa en sí mismo, sino al desinterés por prepararse para el uso de las TIC, lo cual puede ser más acentuado en docentes mayores y cuando se desconocen la misión, la visión y el perfil del profesional que se quiere formar.

Otro factor que podría torpedear la aplicación de este tipo de iniciativas tiene que ver con el mayor trabajo que supone, pues el docente tendría que apartar un espacio de su tiempo para trabajar con los alumnos de manera presencial y virtual.

Aunado a esto, se debe tomar en cuenta que uno de los inconvenientes más difíciles de solventar es el acceso a internet en las zonas rurales. Además, el factor económico es otro factor que pudiese impedir el desarrollo de este tipo de propuestas, pues en algunos casos los profesores sienten que no existe una motivación económica o un estímulo para seguirse preparando en el uso de las TIC.

En síntesis, se puede concluir que muchos de los docentes consultados desconocen el tipo de tecnología que pueden emplear para promover los procesos de enseñanza-aprendizaje de los alumnos. 

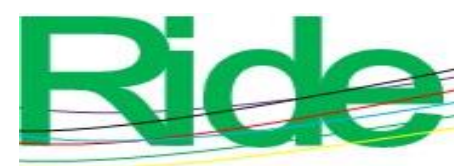

Revista Iberoamericana para la Investigación y el Desarrollo Educativo ISSN 2007 - 7467

\section{Contribuciones a futuras líneas de investigación}

Como futuras líneas de investigación se propone que, a través de la capacitación de los docentes dentro del ámbito rural en el manejo de las TIC, esto mediante la aplicación de diversas estrategias pedagógicas que deban ser introducidas dentro del aula como un efecto motivador en los estudiantes de cualquier institución educativa, y de manera particular las que esten fuera de la zona urbana de los municipios, de cada uno de los departamentos en la república de Colombia. Permitiendo con ello un efecto motivador en el educando en cuanto el aprendizaje de cualquier tema en cada una de sus asignaturas que se imparten; y que sean un verdadero impacto en cada uno de los procesos de enseñanza aprendizaje; esto a través de simuladores en materias como física o matemáticas, el uso de enciclopedias interactivas, el manejo de las redes sociales con un sentido pedagógico para realizar sus actividades académicas, los videos relacionados con temas de interés. Para lograr este propósito el docente rural deberá estar involucrado en cuanto al diseño de diversas metodologías constructivistas que sean adecuadas para el desarrollo de competencias ciudadanas en los estudiantes y que se vean reflejadas en un mayor rendimiento escolar. Además, de generar compromisos en sus diversas actividades académicas de los estudiantes, docentes, padres de familia para la mejora de la calidad de la educación en su comunidad educativa y dentro de su contexto social. 


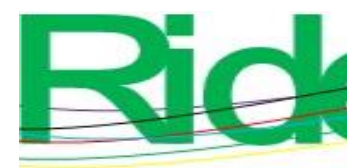

Revista Iberoamericana para la Investigación y el Desarrollo Educativo

ISSN $2007-7467$

\section{Referencias}

Aguerrondo, Inés. (2012). La calidad de la educación: Ejes para su definición y evaluación. La Educación. 37(116) (pp. 561-578). Disponible versión digital en: http://www.educoas.org/portal/bdigital/contenido/laeduca/laeduca_116/articulo4/ind ex.aspx?culture=es\&navid=201.

Aviram, A. (2002) School is out. In: Aviram, A \& Richardson J. (eds.) On What Does the Turtle Stand: An Inquiry into the Aims of the Introduction of ICT to Education forthcoming (pp. 214-248). Editorial Trillas.

Barroso, J. (2012). Docudrama y otras formas en el límite de la ficción televisiva española. En M. L. Ortega, Nada es lo que parece. Falsos documentales, hibridaciones y mestizajes del documental en España (pp.171-206). Madrid: Ocho y Medio.

Beck, U. (1998). ¿Qué es la globalización? Falacias del globalismo, respuestas a la globalización (pp.45-109). Barcelona: Paidós.

Beeby, C.(1976). Aspectos cualitativos de la planificación educativa.México:Avante. (p. 27).

Beltrán, J. (2003). Enseñar a aprender. México: Educared.

Blanco, R. (2008). Eficacia escolar desde el enfoque de calidad de educación. En Valdés, H. (coord.), Eficacia escolar y factores asociados en América Latina y el Caribe (pp. 716). Chile: Santiago.

Brumat, R. y Baca, C. (2015). Prácticas docentes en contextos de ruralidad. Un estudio en escuelas rurales del norte de Córdoba. Educación, Formación e Investigación, (pp. 116). 1(2).

Brunner, J. (2011). Educación: escenarios de futuro. Nuevas tecnologías y sociedad de la información (p. 227). Argentina: PREAL.

Cabero, J. (2015). Las nuevas tecnologías y las transformaciones de las instituciones educativas (pp. 218-228). Granada: Grupo Editorial Universitario.

Castro, H. y Reboratti, C. (2008). Revisión del concepto de ruralidad en la Argentina y alternativas posibles para su redefinición (p. 15). Buenos Aires: Serie Estudios e Investigaciones.

Coll, C., Rosera, M., Mayordomo, R. y Naranjo, M. (2007). Evaluación continuada y apoyo al aprendizaje. Una experiencia de innovación educativa con el apoyo de las TIC en educación superior (pp. 783-804). Revista Electrónica de Investigación Psicoeducativa, 5(13). 


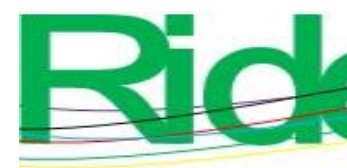

Revista Iberoamericana para la
Investigación y el Desarrollo Educativo
ISSN $2007-7467$

Cruz, M. y Juárez, D. (2018). Educación rural en El Salvador y México: el caso de escuelas unitarias. Revista Interamericana de Educación de Adultos (p. 40). Recuperado de https://www.researchgate.net/publication/322231824_Educacion_rural_en_El_ Salvador_y_Mexico_los_casos_de_escuelas_primarias_unitarias

De Pablos, J. (2007). El cambio metodológico en el Espacio Europeo de Educación Superior y el papel de las tecnologías de la información y la comunicación (pp. 31-53). Revista Iberoamericana de Educación a Distancia.

García Hoz, V. (1981). La calidad de la educación: Una interrogante a las ciencias de la educación, a la política docente y a la actividad escolar. En Escuela Asturiana de Estudios Hispánicos (Ed.), La calidad de la educación: Exigencias científicas y condicionamientos individuales y sociales: [ponencias de un seminario] (pp. 9-23). Madrid: CSIC, Instituto de Pedagogía "San José de Calasanz".

Guhl, E. et al. (1956). La educación rural en Caldas. En Cataño, G. (ed.), Educación y saciedad en Colombia (pp. 25-35). Bogotá: Universidad Pedagógica Nacional.

Instituto Nacional de Formación Docente (2007). Lineamientos curriculares para la formación docente inicial (pp. 12-21). Ley de Educación Nacional № 26206

Itzcovich, G. (2010). Contextos rurales: continuidades y rupturas en el acceso a la educación (p. 28). Argentina: IIPE - UNESCO.

Lorenzatti, M., Brumat, M. y Beinotti, B. (2014). Políticas de formación docente inicial para educación rural en Argentina (pp. 45-55). Revista Iberoamericana de Evaluación Educativa, 7(3).

Lozano, D. (2012). Contribuciones de la educación rural en Colombia, a la construcción social de pequeños municipios y al desarrollo rural (pp. 117-136) Agrópolis, (57).

Majó, J. y Marqués, P. (2014). La revolución educativa en la era Internet (p. 738). Barcelona: CissPraxis.

Morín, E. (2007). Unir los conocimientos. El desafío del siglo XXI (pp. 465-472) La Paz: Plural.

Orden Hoz, A. de la. (1981). Evaluación del aprendizaje y calidad de la educación. En Escuela Asturiana de Estudios Hispánicos (Ed.), La calidad de la educación: Exigencias científicas y condicionamientos individuales y sociales: [ponencias de un seminario] (pp. 111-132) CSIC, Instituto de Pedagogía "San José de Calasanz". 


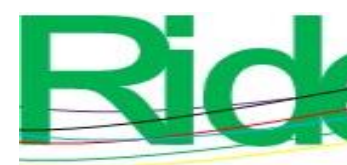

\section{Revista Iberoamericana para la Investigación y el Desarrollo Educativo ISSN 2007 - 7467}

Páez, D., Fernández, I. \& Mayordomo, S. (2000). Alexitimia y cultura. En D. Páez \& M. M. Casullo (Comps.), Cultura y Alexitimia: ¿Cómo expresamos aquello que sentimos? (pp. 51-71). Buenos Aires: Paidós.

Paniagua, V. M. (2003). Integración escolar y calidad educativa: opciones para lograr la equidad (pp. 21-34). México: Educar.

Pérez, E. (2001). Hacia una nueva visión de lo rural. En N. Giarraca, ¿Una nueva ruralidad en América Latina? (pp. 17-30). Buenos Aires: CLACSO. Recuperado el 24 de agosto de 2006 de www.clacso.Edu.ar

Ramírez, M. (2014). Administración de objetos de aprendizaje en educación a distancia: experiencia de colaboración interinstitucional. En Lozano, A. y V. Burgos, (comps.), Tecnología educativa en un modelo de educación a distancia centrado en la persona (pp. 351-373). México: Limusa.

Romero, J. (2012). Lo rural y la ruralidad en América Latina: categorías conceptuales en debate. Psicoperspectivas. Individuo y Sociedad (pp. 8-13). 11(1).

Saad, M. (2007). Universidad y producción de conocimiento científico con un enfoque transdisciplinar: una experiencia dentro de la maestría en Educación (pp. 1-34). Revista Educere, 11(37).

Seibold, J. (2014). Equidad en la educación. La calidad integral en educación (pp. 1-34). Revista Iberoamericana de Educación, (23).

UNESCO (2012). Estándares de competencias en TIC para docentes (pp.9-16). Londres Recuperado de http://www.eduteka.org/EstandaresDocentesUnesco.php UNESCO (2013). Education in and for the Information Society (pp. 7-14). París: Unesco.

Vargas, N. (2014). Concepto de ruralidad. Pedagogía y Ruralidad (p. 28). Recuperado de http://pedagorural.blogspot.com.co/2014/07/concepto-de-ruralidad.html

Zamora, L. (2015). Seminario de educación rural. Bogotá: Universidad Pedagógica Nacional. 


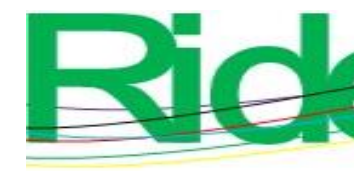

Revista Iberoamericana para la
Investigación y el Desarrollo Educativo
ISSN $2007-7467$

\section{Francisco Flores Cuevas}

Doctor en Gerencia y Polítuca Educativa Universidad de Baja California, Maestro en Educación por la Universidad del Valle de Atemajac UNIVA, Licenciado en Informática Instituto Tecnológico de Ciudad Guzmán. Diplomados en Competencias Docentes Universidad de Arizona, Certificación de Cisco IT Essential, Diplomado en Educación a Distancia Universidad de San Diego, California USA, Diplomado en Competencias Docentes para el Siglo XXI por el Tec de Monterrey en convenio con la Universidad de Cambridge, England. Es catedrático de tiempo completo en la Universidad de Guadalajara, Campus CUCosta Puerto Vallarta, docente y asesor de tesis doctorales de la Universidad de Baja California. Líder del cuerpo académico en consolidación UDG-CA 653 "Tecnologías Aplicadas a la Educación”. Perfil PRODEP Nivel XVII. Autor de mas de 15 libros relacionados con Competencias docentes y de mas de 25 artículos publicados en revistas nacionales e internacionales.

\section{Claudio Rafael Vásquez Martínez}

Doctor en Educación Universidad Autónoma de Guadalajara, Maestro en Sociología de la Educación Universidad de Antioquia Medellin Colombia, Licenciado en Tecnología Industrial Universidad de San Buenaventura Medellin Colombia. Diplomados en Competencias Docentes Universidad de Arizona, Doctorado Honoris Causa por la Universidad Autónoma de Nayarit, Galardonado por el H. Ayuntamiento de Puerto Vallarta y por la Universidad de Guadalajara. Es catedrático de tiempo completo Titular C en la Universidad de Guadalajara, Campus CUCosta Puerto Vallarta, docente y asesor de tesis doctorales de la Universidad de Baja California. Miembro del cuerpo académico en consolidación UDG-CA 653 “Tecnologías Aplicadas a la Educación”. Perfil PRODEP Nivel XVII. Candidato al Sistema Nacional de Investigadores. Ha publicado un libro y varios artículos en revistas nacionales e internacionales. 


\section{Revista Iberoamericana para la Investigación y el Desarrollo Educativo ISSN 2007 - 7467}

\section{Heriberto Campos López}

Doctor en Desarrollo Sustentable Universidad de Guadalajara, Maestro en Derecho Penal y Abogado por la Universidad de Guadalajara Campus Puerto Vallarta, Jalisco. Diversos diplomados disciplinares en formación docente por la Universidad de Guadalajara dentro de los programas para el Fortalecimiento Docente y del PROINNOVA. Es catedrático de tiempo completo en la Universidad de Guadalajara, Campus CUCOSTA con sede en Puerto Vallarta Jalisco, y actualmente funge como presidente de academia de Derecho Laboral. Cuenta con Perfil Deseable del Programa de Mejoramiento del Profesorado (Promep). Ha publicado libros y varios artículos en revistas nacionales e internacionales.

\begin{tabular}{|l|l|}
\hline Rol de Contribución & Autor (es) \\
\hline Conceptualización & Francisco Flores Cuevas \\
\hline Metodología & Francisco Flores Cuevas \\
\hline Software & Francisco Flores Cuevas \\
\hline Validación & Claudio Rafael Vásquez Martínez \\
\hline Análisis Formal & Claudio Rafael Vásquez Martínez \\
\hline Investigación & Francisco Flores Cuevas \\
\hline Recursos & Francisco Flores Cuevas \\
\hline Curación de datos & Heriberto Campos López \\
\hline $\begin{array}{l}\text { Escritura - Preparación del borrador } \\
\text { original }\end{array}$ & Heriberto Campos López \\
\hline Escritura - Revisión y edición & Claudio Rafael Vásquez Martínez \\
\hline Visualización & Heriberto Campos López \\
\hline Supervisión & Francisco Flores Cuevas \\
\hline Administración de Proyectos & Francisco Flores Cuevas \\
\hline Adquisición de fondos & Francisco Flores Cuevas \\
\hline
\end{tabular}

